\title{
Innovation Research on Training Mode of In-service Teachers in Rural Primary and Secondary Schools
}

\author{
Jun Yang \\ School of Education and Sports, Bohai University, Jinzhou, 121013, China \\ 444530141@qq.com
}

Keywords: rural teachers; in-service teachers; training mode; innovation

\begin{abstract}
How to train teachers in rural primary and secondary schools, are related to the improvement of the overall quality of rural teachers and the improvement of the quality of compulsory education. The application research of the innovative teacher training mode, to explore a more targeted, effective rural teacher training mode has become an urgent task. We are based on the full investigation, reconstructed the theoretical research framework of the rural teacher training mode: "246" training mode: namely two stages, "centralized training stage" and "on-the-job practice stage"; "centralized training phase" complete four modules, namely "professional lead," "teaching practice", "summed improvement", "decentralized training"; "on-the-job practice phase" used six school-based or six ways of decentralized training to complete training.
\end{abstract}

\section{Introduction}

China's current approximately 14 million primary and secondary teachers, which the number of rural teachers accounts for about three-quarters, which indicates that a large group of rural teachers is the main force of China's education. At the same time, rural teachers are the key to building a new socialist countryside, developing the rural basic education and improving the quality of education in rural schools. But along with the curriculum reform of basic education, the promotion of teacher appointment system, the implementation of teacher qualification system, rural teachers are facing more and more problems. With the proposed of teachers' concept of lifelong learning, and actively carry out in-service education training of rural teachers, improve the overall quality of rural teachers, but also the requirements proposed by party and the government for rural primary and middle teachers, so the training of rural teachers is also an urgent need to solve the problem [1].

This is a regional meso-study face the special teachers colony (rural primary and secondary teachers), is fully aware of the difficulties, confusion and problems in the teaching of compulsory education, and fully understand the actual needs of primary and secondary school teachers and basic on the training expectations, to reconstructed the theoretical framework of rural teacher training mode: "246" training mode. The study innovate the application research of teacher training mode, the focus is to explore a more targeted, effective teacher training mode, the purpose is to provide a scientific basis for decision-making reform of continuing education for teachers.

\section{Training Status on In-service Teachers in Rural Primary and Secondary Schools}

Training is lack of institution and conditions guarantee. Examine various systems of education training in current primary and middle schools teachers, primarily for the Ministry of Education issued the " primary and secondary school teachers' continuing education provision", but because there is a big difference between urban and rural education, this unity demands and policies lack targeted, for rural teacher training in theoretical research and practical operation have become less effective. At the same time, many rural educational administrative departments and schools have not set up a teacher training program, or if it developed a training program, but because of the lack of guarantee condition, and not the specific implementation. But there is not a higher administrative department planning clarity, support provided by the school have also been insufficient, coupled with continuing training for teachers themselves are not active, naturally makes training difficult to 
achieve tangible results. In addition, lifelong education and adult education in the legislation is lag, also makes teacher training lack of strong policy support.

Training management standardization is weak. In aspect of training objectives, targeting point to biased participating teachers understand and grasp for theoretical knowledge, practical ability is difficult to continuously improve; in training concept, to theoretical indoctrination is the main, or case interpretation is the main, lead to a serious gap between theory and practice, teachers participating in the training is difficult to put theory into practice behavior; in the training content, expressed as "two unification": unified textbooks, unified form, there is no geographical targeted, at different stages of development without considering the needs of teachers participating differences; due to lack of institutional support, fund guarantee and human resources, the construction of rural teacher training course is backward, lack of course resources has hindered the rural teachers' training work; In the form of teacher training, the means is single, and form is monotonous; In training management, relying on the administrative organization, the emphasis on discipline, pay attention to the attendance check, focusing on the graduation exam, do not conform to the characteristics of adult learning, not respect for teachers management rules, in terms of training opportunities, $32.03 \%$ of teachers think that the training is not much, The basic way to participate in the training is to rely on the higher education administrative departments to allocate; in terms of training time, the rural teacher training time focused on two aspects, in school time and holidays focus on learning, and the length of training time also affected the status of teacher training [2].

Training effect and evaluation is not good. Currently, supporting evaluation mechanism on teacher training has not yet been fully established, teacher evaluation is still a traditional paper and pencil examination after training, so that the enthusiasm of teacher training and learning is difficult to stimulate. Confined to this, teacher training basically become a terminal education, when the "card" get the hand, it is also the end of the training learning, but extremely lack of continuity tracking service, eventually leading to poor sustainability of teacher training, lack of stamina and endurance loss [3].

\section{Training Strategy and Advice on In-service Teachers in Rural}

Increase economic investment, to provide policy support. In combination with the new situation of the new development period to make changes and adjustments, accelerate and regulations construction on teacher education, adult education, lifelong education, the implementation of teacher training institutions qualification certification system, teacher training quality grade and teacher training course appraisal system. At the same time, should also establish teacher training and personnel system reform and teacher qualifications combining institutional system, in particular, to the introduction of the rural teacher training relevant rules and regulations, the implementation of preferential policies for rural teacher training; secondly, the establishment of rural teacher training to ensure funding mechanism, to establish rural compulsory education funds system of various levels of financial allocation, shared by the central, provincial, city, county, basic education in rural poor areas to implement policies, ensure rural compulsory education in basic inputs, establishment of special funds for rural teacher training, to improve school conditions of teacher training institutions, and create favorable conditions for rural teachers' professional development [4] .

Integrate training resources and create training conditions. Rural teacher training should be added to the construction of facilities, teachers, course, management and other aspects, the mobilization of a wide range of teacher education resources, encourage local institutions to play their own advantages, actively integrate a variety of training resources, including human resources,

course resources, setting resources, to achieve training trainers, course, teaching, setting, network and other resources sharing, complementary advantages, improve the training mechanism, to provide resources guarantee for the rural teacher training.

Updated training concepts, improve training targeted. Establish the concept of lifelong education, teacher training under the guidance of the overall goal, selected training content according to the current situation and the actual needs of rural teachers, from the reality of rural teachers try to meet their actual needs, strengthen the relevance and applicability of training, reflecting according to the 
demand teach. The same training methods cannot be confined to the traditional "teachers themselves speak a lesson, the students listen to the whole class", should be based on different training content and objects, using a variety of training methods to improve the practicality and effectiveness of the training: Such as the use of cooperative inquiry way, through learning together to seek a variety of solutions, in the process of cooperation, teachers can not only learn from the training, and can also share experiences with other teachers, give full play to the positive initiative of teachers; also take the form of case teaching, through observation, experience and feel the real teaching process demonstrated by the education new concept, increasing teachers' practical learning, effectively increasing the training operability; can also encourage teachers to carry out autonomous learning, teachers according to their own demand in the guidance of trainers, independent practice, multi-evaluation, and constantly self-improvement, this training method can make the teachers choose self-study mode and the teaching materials according to their actual situation, to teach students in accordance with their aptitude. It should be based on different training content and objects, using a variety of training methods to improve the practicality and effectiveness of the training: such as the use of cooperative inquiry methods [5].

Enrich training content, training in various forms. In the training process to teachers to pay more attention to the individual differences, because different levels, different types of teachers from different disciplines require different training content, profession strong and rank difference more obvious in the training content should be small class, seminar-style, inquiry type. At the same time it should be combined with the actual situation of the school, concerned about the effectiveness of the training. The traditional lecture style training is no longer favored by teachers, field trips and observes teaching training by the teacher's pursuit, the highest degree of concern, but also training in the future need to work hard in this direction [6].

Improve the evaluation system, enhance training effectiveness. First of all, to establish an effective monitoring, evaluation, incentives mechanism to improve the quality of training, and supervision by the rural teacher training, evaluation, incentives to promote rural teacher training depth development; secondly, in the main aspects of the evaluation, should be involved in training schools, teachers, trainers and other fully involved, and continue to find issues, a comprehensive and detailed assessment; In terms of the evaluation object, the effectiveness of training, teacher training institutions and evaluation should be strengthened; in the aspect of evaluation goals, to pay more attention evaluation of the training process; in terms of evaluation means, evaluation index should meet the actual training, strengthening scientific quantitative evaluation; and finally, to establish a long-term effective incentive mechanism to mobilize the rural teacher training initiative. Put their training into human resource management process, the training and teacher qualification certification, appointment, assessment, promotion, incentives to contact each other, in order to promote rural teachers to improve their professional qualities. To attach importance to and support the unit teacher training and the principal to reward; for the attention and to take effective measures to support teacher training counties reward; through improving service quality, innovative training mode, to effectively meet the training needs of trainers and training institutions staff reward.

\section{Training Innovation Mode on In-service Teachers in Rural}

Training mode innovation in-service teacher in rural, that is, "246" training mode, shown in Fig. 1.

(1) "Two" stage. "Two" refers to the two stages, namely "centralized training stage" and "on-the-job practice stage". "Centralized training stage" has organized a total 30 days, arranged for the learner in the city training school teachers to accept concentrated training. The training content mainly includes moral cultivation, new course and classroom teaching, modern educational theory, educational research, head teacher training, teacher knowledge development and other six areas. Another is " on-the-job practice stage", on-the-job practice stage totaling 10 months, after the end of the concentrated training, return to own school to participate in school-based training prescribed school hour, the theoretical knowledge and teaching practice are combined, the existing problem for teaching to carry out targeted research and complete research reports or teaching papers. Only two stages of training are qualified to issue training certificates and continuing education certificates. 
This will not only help teachers to link theory with practice, apply their knowledge, to promote sustainable development of teacher education.

(2) "Four" modules. "Four" refers to the four modules of concentrated training stages. That is "professional guide", "teaching practice", "summed improvement", and "decentralized training". In the centralized training stage, according to the four modules organize training. The first module is the "professional guide" through the multiple teaching staff, carry on the leading of professional ethics, teaching concept, discipline knowledge and skills, and the teaching methods. The second module is a "teaching practice", organized the learner to point-to-school teaching practice for a week, the professional instructor throughout the guide, and launched research class, reporting class, open class. The third module is a "summary and improvement", together with the students and teachers to reflect, summarize and exchange of learning and practice insights, experience and harvest, as the backbone of the training participants and training to lay the foundation. The fourth module is a "decentralized training" stage, the end of concentrated training, learner return to the school where decentralized training and complete the training mission.

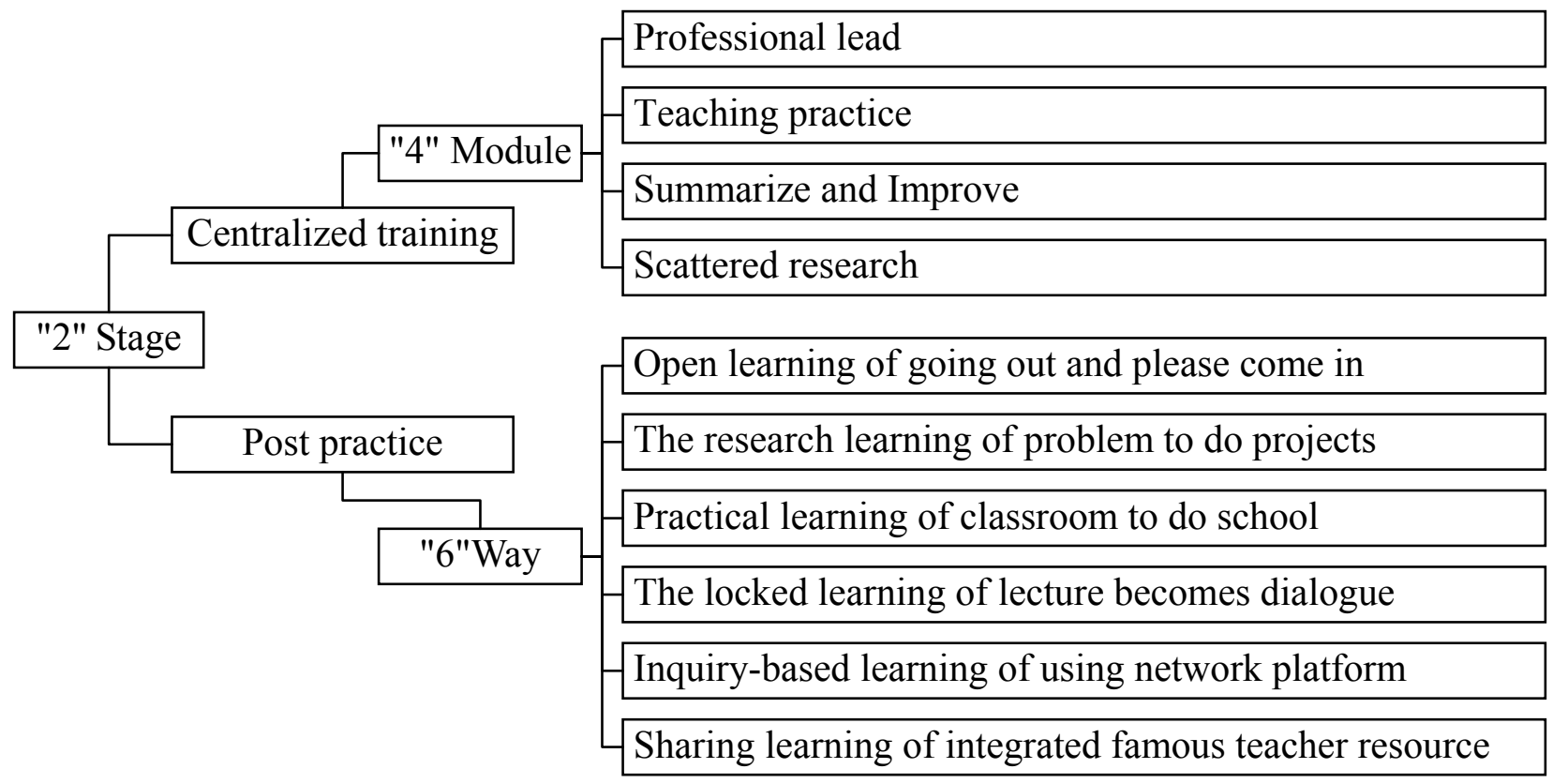

Fig. 1. Training innovation mode on in-service teachers in rural

(3) "Six" kind of way. "Six" means "on-the-job practice stage", after the learner focused on training, back to school to participate in school-based training where the prescribed school time, complete the appropriate assignments, or to complete the required decentralized training tasks. During this period, using six school-based training or 6 kinds of ways of decentralized training.

The open learning that is going out and please come in. Going out refers to the planned organization of teachers and principals out to other high quality or characteristics of the school to learn, or to send teachers to the field to conduct lectures exchanges; please come in refers to invite some of the curriculum reform specialist or educator came to the school to give lectures, with teachers direct dialogue and exchanges. School can also organize experts to conduct on-site training, from the perspective of the theory to examine the self, to realize the sublimation of knowledge.

Research learning is through the problem-based to do the projects. Each school in the specific teaching practice, there will be many common problems and personality issues. Teachers in various schools can turn into the original form of teaching and research into a problem research type of research, and the teachers' research results published in the open, to encourage teachers to carry out research, to promote teaching activities.

Practical learning is about classroom to do the school. On the one hand, we have the initiative in the classroom to give students, students will put forward many problems that teachers cannot be preset, teachers lead students in the process of solving these problems, there must be a new upgrade, that is, and we say the teaching benefits teachers as well as students. On the other hand, we mention 
the scene to observe classroom teaching will be held, a common share lesson, to analyze the gains and losses about the classroom teaching, to improve the effectiveness of the teacher learning.

The locked learning is about lecture becomes dialogue. Most previous training is to take a ready manuscript give teacher speak, so the effect is often not good, lectures become dialogue is to determine a topic and then allow teachers to ask questions, about the problem raised by the teachers, can hire curriculum reform specialists, curriculum reform famous teacher, of course, can also be outstanding teachers of the school to engage in dialogue, to answer, so that can be targeted, you can lock the need to solve problems and improve the effectiveness of learning and training.

Inquiry learning is using the Internet platform. Give full play to the role of network education platform, to take a mixed learning approach, the teacher online learning and not online centralized research is combined. Promote and encourage teachers to write articles about education and teaching made to share with others on the blog; also can often put forward some problems of educational aspects, so that everyone in the online discussion.

Integration of teacher resources shared learning. Set up a teacher's club, through the organization to integrate the excellent teacher resources. In education ideas, educational ideas, educational model research, teacher role orientation, educational technology, and so on, a series of issues to in-depth discussion, Discussion results allow teachers to share. In this way, not only for the growth of these teachers to build a broader platform, but also led to the continuous improvement of all teachers.

\section{Conclusion}

In fact, there is no one kind of teacher professional development training model will be suitable for any person at any time. The "246" training mode provides a useful inspiration for the in-service training of rural primary and middle school teachers. It also puts forward the creative training program for the country's basic education department, should fully explore and integrate training resources, improve school conditions, use the advantages of running a school, improve the training base construction of primary and middle school teachers, and enhance the effectiveness of training. Therefore, the "246" training mode is worthy offurther study, widely promoted and reference.

\section{Acknowledgement}

This work is supported by 2015 annual key issues of economic and social development in Liaoning (2015lslktzimzs-02), 2013 annual "A" class teaching reform project in Bohai University (JG13YB004), 2014 annual "A" class teaching reform project in education department of Liaoning province (UPRP20140249).

\section{References}

[1] Z. Y. Zhang, "Investigation and strategy research on the current situation of rural teacher training," Theory and Practice of Education, vol. 15, no. 1, pp. 14-16, 2011.

[2] X. M. Pan, "Research on problems and countermeasures of rural teacher training," Journal of Hubei University of Education, vol. 14, no. 4, pp. 34-36, 2013.

[3] H. Y. Song, R. Chen, "Thinking on improving the effectiveness of rural teachers training," Education Exploration,, vol. 16, no. 10, pp. 127-129, 2011.

[4] S. H. Zhao, "Northwest rural teacher training model and its countermeasures: Taking the county of Shaanxi Province, Xi'an city as an example," Master's degree of Shaanxi Normal University, 2011.

[5] X. Y. Zhang, "What kind of teacher training: A Study on the needs of rural teachers training," Master's degree of Huazhong Normal University, 2009. 
[6] L. Y. Wang, "Investigation on the current situation of rural middle school teachers training: Taking four counties in Jinzhong as an example," Master's degree of Shanxi Normal University, 2014. 